University of Pennsylvania Carey Law School

Penn Carey Law: Legal Scholarship Repository

Faculty Scholarship at Penn Carey Law

$12-3-2008$

\title{
Government Clubs: Theory and Evidence from Voluntary Environmental Programs
}

Cary Coglianese

University of Pennsylvania Carey Law School

Jennifer Nash

John F. Kennedy School of Government, Harvard University

Follow this and additional works at: https://scholarship.law.upenn.edu/faculty_scholarship

Part of the Administrative Law Commons, Environmental Policy Commons, Law and Politics

Commons, Law and Society Commons, Policy Design, Analysis, and Evaluation Commons, and the Public

Law and Legal Theory Commons

\section{Repository Citation}

Coglianese, Cary and Nash, Jennifer, "Government Clubs: Theory and Evidence from Voluntary Environmental Programs" (2008). Faculty Scholarship at Penn Carey Law. 243.

https://scholarship.law.upenn.edu/faculty_scholarship/243

This Book Chapter is brought to you for free and open access by Penn Carey Law: Legal Scholarship Repository. It has been accepted for inclusion in Faculty Scholarship at Penn Carey Law by an authorized administrator of Penn Carey Law: Legal Scholarship Repository. For more information, please contact PennlawIR@law.upenn.edu. 


\title{
Government Clubs: Theory and Evidence from Voluntary Environmental Programs
}

\author{
Cary Coglianese \\ Associate Dean for Academic Affairs \\ Edward B. Shils Professor of Law \\ Director, Penn Program on Regulation \\ University of Pennsylvania Law School \\ Jennifer Nash \\ Regulation Fellow \\ John F. Kennedy School of Government \\ Harvard University
}

\begin{abstract}
$\underline{\text { Abstract }}$
The U.S. Environmental Protection Agency (EPA) has established numerous voluntary environmental programs over the last fifteen years, seeking to encourage businesses to make environmental progress beyond what current law requires them to achieve. EPA aims to induce beyond-compliance behavior by offering various forms of recognition and rewards, including relief from otherwise applicable environmental regulations. Despite EPA's emphasis on voluntary programs, relatively few businesses have availed themselves of these programs -- and paradoxically, the programs that offer the most significant regulatory benefits tend to have the fewest members. We explain this paradox by focusing on (a) how programs' membership screening corresponds with membership rewards, and (b) how membership levels correspond, in turn, with membership screening. Our analysis of three major case studies, as well as of data we collected on all of EPA's "green clubs," shows that EPA combines greater rewards with more demanding membership screening, which in turn corresponds with lower participation. EPA's behavior can be understood as a response to the political risks the agency faces when it recognizes and rewards businesses it otherwise is charged with regulating. Given the political constraints on EPA's ability to offer significant inducements to business, we predict participation in all but the most inconsequential voluntary environmental programs will remain quite low, thereby inherently limiting the ultimate value of voluntary programs as a strategy for advancing environmental protection.
\end{abstract}




\title{
Government Clubs: Theory and Evidence from Voluntary Environmental Programs*
}

\author{
Cary Coglianese \\ Jennifer Nash
}

Governments increasingly use voluntary environmental programs -- or what Aseem Prakash and Matthew Potoski (2006, 2008) have called "green clubs” -- to try to achieve environmental results (Fiorino 2008). In this paper, we analyze the way green clubs run by the U.S. Environmental Protection Agency (EPA) manage a tension inherent in all clubs: attracting members while upholding standards. As Potoski and Prakash (2008) have explained, the positive social externalities a green club achieves will depend both on the number of club members as well as the requirements for membership. The challenge for institutions that establish green clubs is to encourage large numbers of facilities to join while maintaining rigorous conditions for entry and ongoing membership.

All things being equal, the greater the benefits that can be offered to members, the more readily clubs can achieve both high membership rolls and high standards. Many

\footnotetext{
* A revised version of this paper is forthcoming in Matthew Potoski and Aseem Prakash, eds., Voluntary Programs: A Club Theory Approach (Cambridge: MIT Press). Gopal Raman provided invaluable research assistance in many facets of this project, most especially with coding and collecting data. We are also grateful for helpful comments we received from Natasha BeschTurner, Dan Fiorino, Deb Gallagher, Peter May, John Mendeloff, Dinah Koehler, Matt Potoski, Aseem Prakash, Evan Ringquist, Thane Thompson, Michael Toffel, and Terry Yosie. We presented an earlier version of this paper at the 2005 meeting of the Association of Public Policy and Management and appreciate the comments of participants. Our research was supported by the United States Environmental Protection Agency, Office of Policy, Economics, and Innovation (Grant No. R-83056701), as well as by an award from the Corporate Social Responsibility Initiative at Harvard University's John F. Kennedy School of Government. We alone - and neither our funders nor colleagues - are responsible for the views and conclusions expressed herein.
} 
green clubs, like the nongovernmental ISO 14001 (Prakash \& Potoski 2006), only promise enhanced reputation, that is, the possibility that investors, employees, and environmental regulators will look upon members more favorably (Lyon \& Maxwell 2004). Green clubs run by government, by contrast, can offer members more than an enhanced reputation; they can also offer relief from regulatory requirements. For example, the U.S. Environmental Protection Agency’s (EPA) Performance Track program offers its members a low priority for routine regulatory inspections and the reduction in burdens associated with reporting and permitting regulations (Fiorino 2008). Only green clubs run by government can offer such regulatory benefits, so it would seem that government clubs would have a clear advantage when it comes to attracting members that meet high standards, at least compared to clubs run by other institutions.

Surprisingly, though, membership in some nongovernmental clubs significantly dwarfs membership in comparable governmental clubs. ISO 14001 has about ten times as many members in the United States as does EPA's Performance Track program, even though both have similar requirements and even though membership in Performance Track offers greater rewards than does ISO. After eight years of operation as EPA's flagship voluntary program, however, Performance Track has only been able to recruit and retain about 550 individual facilities from across the nation, a fraction of the facilities with ISO-compliant environmental management systems. Assuming Performance Track's experience is emblematic of government clubs more generally, why has the level of participation in government clubs remained comparatively low?

In this paper, we investigate why government clubs with the greatest benefits paradoxically have the fewest members. We explain this puzzling outcome by focusing 
on (a) the relationship between clubs' entry procedures and the rewards they offer members, and (b) the relationship between membership levels and entry procedures. While government agencies in theory have the most to offer facilities that participate in their voluntary programs, in practice these agencies face a political environment that leads them to combine greater rewards with more demanding entry requirements. As Fiorino (2008) indicates, conferring benefits on individual regulated entities is a "delicate matter" for government officials, particularly when the benefits take the form of regulatory relief.

Our analysis accepts club theory's premise of a tradeoff between attracting members and preventing them from shirking (Potoski \& Prakash 2008). We show that government clubs can achieve one or the other of these objectives -- high growth or high standards -- but not both. As a result, unlike Fiorino (2008) who optimistically views government clubs as "a path for systemic change,” we suggest at best a substantially more limited role for government clubs. Club theory and our data lead us to predict that the level of participation in government clubs continue to remain relatively low, especially when they offer substantial membership rewards. These rewards are simply not significant enough for many firms to overcome the additional demands agencies place on potential members who are to receive those additional rewards. If "clubs with few members can hardly be considered successful” (Prakash \& Potoski 2006, 21), then in contrast with Fiorino (2008), we actually should expect very little from government clubs, notwithstanding their ability to offer additional inducements for membership. 


\section{Club Design and Participation}

As Potoski and Prakash (2008) have emphasized, green clubs meet the challenges of attracting members and enforcing club standards through institutional attributes that provide sufficient incentives for businesses to join, while still ensuring adequate monitoring and enforcement of standards. Prakash and Potoski’s (2006) emphasis on institutional design points to an important way of explaining membership levels across green clubs. At least until Prakash and Potoski's work, scholars had paid remarkably little attention to how the design of voluntary environmental programs might affect participation. In a comprehensive review of the literature on voluntary programs, for example, Lyon and Maxwell (2002) offered a series of eight important factors affecting participation in voluntary programs and these programs' performance - none of which directly related to the issue of program design. The relative lack of attention to the design of voluntary programs is striking because any potential member's assessment of the costs and benefits of participation presumably rests not only on its own business model and organizational characteristics, but also on what kinds of benefits and costs the voluntary program actually offers and imposes. ${ }^{1}$

\footnotetext{
${ }^{1}$ The rewards offered to members, and the behavior expected of them to join and remain in the club, are key aspects of what we mean by a club's institutional design. To be sure, several previous studies have noted that positive inducements offered by clubs can motivate participation (Segerson and Li 1999; Davies and Mazurek 1996; Khanna 2001). Others recognize that government can offer different types of membership benefits than nongovernmental organizations. In addition to offering technical information about ways to reduce waste and other forms of pollution (Khanna 2001; Delmas and Keller 2005), government can offer regulatory or procedural flexibility to participating firms (Delmas and Terlaak 2001; EPA 1998). Other government programs seek to encourage firms to undertake action that can benefit their bottom line, such as through energy efficiency or other actions that firms presumably have an incentive to take even in the absence of the program (Morgenstern \& Pizer 2006).
} 
One reason institutional design has been so little emphasized may be that existing research has used the individual firm as the unit of analysis, seeking to explain varying firms' decisions while holding the voluntary program - or government club - constant. For example, Khanna and Damon (1999) and Arora and Cason $(1995,1996)$ analyze differences between participants and non-participants in the EPA's 33/50 program, while Prakash and Potoski (2006) use a single club - ISO 14001 - as their main example. Restricting attention to participation in individual voluntary programs has allowed researchers to gain analytical traction on the firm- or facility-level characteristics that correlate with participation. However, such an approach does not allow researchers to assess whether or how differences in program design may also influence firms' decisions.

To see how design differences may affect participation, we begin by considering three of EPA's most prominent voluntary programs: (1) the 33/50 program, (2) Performance Track, and (3) Project XL. For each, we describe the package of benefits EPA has offered and the standards it has set for entry and ongoing participation. We also describe the numbers and characteristics of facilities that have joined each program. These three programs represent a progression in terms of their standards for participation and the rewards they offer. Although EPA has given high priority to each of these programs, membership in them has varied substantially. The 33/50 program engaged roughly twenty-five times the number of facilities as Project XL, and membership in Performance Track lies between the extremes of 33/50 and XL. 


\section{The 33/50 Program}

EPA’s 33/50 program, launched in early 1991, sought to encourage businesses voluntarily to reduce emissions and transfers of seventeen targeted chemicals required to be reported under the Toxics Release Inventory (TRI), an environmental disclosure system that Congress mandated in 1986 under the Emergency Planning and Community Right to Know Act. The program received the name 33/50 because it aimed to reduce TRI releases of the targeted chemicals by 33 percent by 1992 and 50 percent by 1995 .

EPA developed its list of seventeen targeted chemicals by asking its regulatory offices to name their high-priority chemicals. Any TRI chemical making the list of more than one office came under the rubric of 33/50. The program's interim goal of $33 \%$ and its ultimate goal of 50\% were based largely on a suggestion made in an earlier report published by the Office of Technology Assessment that a 50\% reduction in toxic releases would be feasible (U.S. Congress, 1986).

Any company that released any one of the targeted chemicals was eligible to participate. To join, a company needed only to commit to reducing at least one of these chemicals -- and to do so by any amount. The 33\% and 50\% reduction goals applied to overall emissions of the targeted chemicals, not necessarily targets for individual businesses.

EPA faced the decision of what baseline year to use to measure the attainment of their toxics reduction goals. Companies and trade associations that had already undertaken major efforts to reduce toxic releases before 1991 argued against using 1991 or 1990 as a baseline year because it might advantage those companies who waited longer to begin reducing releases. According to EPA staff, industry also wanted to make 
the voluntary program a success by meeting EPA's reduction goal, something that would be more assured if the agency selected an earlier baseline year. In the end, EPA used a 1988 baseline, which in early 1991 was the most recent year for which aggregate data on toxics releases were available.

EPA actively recruited companies to join the program, targeting at the outset those companies with facilities having the largest volumes of toxic releases (Khanna 2006). EPA sent an initial batch of invitation letters to CEOs of the "Top 600" companies, which together accounted for about $66 \%$ of releases of the 17 targeted chemicals based on 1988 data (EPA 1999). Of these businesses, 328 (64\%) chose to join (Khanna 2006). In July, 1991, EPA sent letters to an additional 5,400 companies and followed up with telephone calls. It sent out a third round of invitations in 1992, to an additional 2,512 companies (Khanna 2006). The businesses EPA contacted in the second and third rounds were smaller in size, had lower releases than the initial “Top 600” group, and were relatively less responsive to EPA's invitation, with only about $13 \%$ signing up (Davies \& Mazurek 1996). Out of about 10,000 companies eligible for the program because they reported toxic releases, EPA overall invited about 8,000 to participate and, by the end of the program, about 1,300 facilities had joined (EPA 1999, Khanna 2006).

Perhaps not surprisingly given EPA's initial outreach to businesses with the largest volumes of toxic releases, 33/50 participants tended overall to be large, profitable businesses with large emissions (Arora \& Cason 1995, Gamper-Rabindran 2006). They also tended to market their products directly to consumers, have large advertising and R\&D budgets (Arora \& Cason 1996), and be publicly traded (Gamper-Rabindran 2006). 
Beyond these common features, other characteristics varied according to participants' sector. In the transport industry, for example, plants surrounded by poorer households were less likely to participate. In the chemical industry, plants were more likely to join if EPA had recently inspected them (Gamper-Rabindran 2006).

For businesses that joined, participation costs were minimal. A manager simply had to write EPA a short letter committing to reduce any amount of one or all of the 17 targeted chemicals against their 1988 level of releases. ${ }^{2}$ Upon EPA's receipt of such a letter, the company was "in" the 33/50 club. EPA then recognized these companies by sending them a certificate of appreciation signed by the administrator. Commitments were in no way legally binding, and EPA made this clear to participants. EPA encouraged businesses to set their own goals and timeframes. As noted, individual facilities did not need to commit to reducing their own releases by $33 \%$ or $50 \%$. Indeed, a notable proportion of companies - up to $40 \%$ according to a 1995 evaluation commissioned by EPA - received certificates even though EPA could not quantify any specific level of reductions stated in their commitment letters (EPA 1995a). Each company received the same certificate of appreciation regardless of the level of its commitment. Furthermore, EPA made no effort to see whether individual companies followed through on whatever commitments they made.

Overall releases from both participating and non-participating companies declined enough to meet EPA's national 33\% and 50\% goals. By the end of the first year of the program, the total reported releases of the seventeen targeted chemicals were down more

\footnotetext{
${ }^{2}$ EPA even prepared a sample letter, just one paragraph long, for firms to use to make their commitments.
} 
than 33\% compared with 1988 levels. By the end of 1995, total releases of the targeted chemicals had dropped by 55\%, or 824 million pounds, since 1988 (Khanna 2006).

The 33/50 program has been the subject of numerous research studies which present a complex picture of the program's impact (Khanna \& Damon 1999, Sam \& Innes 2005, Gamper-Rabindran 2006). No one seriously thinks that 33/50 led to the entire 56\% reduction in the release of targeted chemicals from 1988-1995. Khanna (2006) observed, based on a review of EPA data (EPA 1999), that 28\% of the reduction attributed to the program occurred in the period 1988-1990, before 33/50 even began. Obviously, these reductions should be attributed to other factors besides $33 / 50 .^{3}$ Furthermore, other TRI chemicals not included in the 33/50 program also declined, suggesting that factors having nothing to do with 33/50 probably contributed to reductions in the targeted chemicals, including preexisting corporate pollution control programs, the closure of facilities, the elimination of product lines, the incentives provided by the public availability of TRI data, and traditional regulations aimed at the targeted chemicals. Indeed, EPA issued a proposed or final rule directed at reducing almost every one of the seventeen target chemicals between 1988 and 1991. The 33/50 chemical having the single largest percentage reduction -- 1,1,1-trichloroethane, an ozone depleting chemical found in industrial solvents -- was subject to a regulatory ban under the Montreal Protocol (EPA 1999). The reductions in this one chemical alone accounted for approximately 20\% of the total reductions in 33/50 chemicals from 1988-1996 (EPA 1999).

\footnotetext{
${ }^{3}$ The General Accounting Office has criticized EPA for adopting the 1988 baseline, arguing that only reductions from the period 1991 to 1994 should be attributed to the program (GAO 1994).
} 
In addition, TRI data themselves raise questions. Since EPA uses industry’s own reporting, if companies devote more attention to estimating their releases they may be able to report reductions on paper that do not necessarily reflect real reductions. Companies also can escape the requirement to report releases if they reduce their use of designated toxic chemicals to below given thresholds, a reporting artifact that may account for as much as $40 \%$ of the reductions in reported releases (Bennear 2008). Of course, concerns about TRI data are not restricted to 33/50 companies, so it might make sense to compare the progress of participants with that of non-participants. According to EPA, participants in 33/50 reduced targeted chemicals by 49\% between 1991-1994, while non-participants reduced the same chemicals by only $30 \%$ during the same time period (Davies \& Mazurek 1996, 15). The overall release of targeted chemicals dropped 42\% during the same period, while other TRI-reported chemicals dropped only 22\% (Davies \& Mazurek 1996, 15). These findings, however, do not take into account the fact that companies signing up for 33/50 may have been predisposed to reduce their releases and that the same factors that led them to join also prompted them to reduce.

Using regression analysis, Khanna and Damon (1999) examined the effect of the program on releases in the chemical industry, reporting that the $33 / 50$ program was associated with about a 28\% decline in the target chemicals during the period 1991-1993. Sam \& Innes (2005) similarly reported that the program corresponded with a reduction in releases and a decline in inspection rates. Gamper-Rabindran $(2006,408)$ eliminated from analysis two 33/50 chemicals required to be phased out under the Montreal Protocol and found that for the remaining 15 chemicals, "the program did not reduce emissions in most industries.” Only in the fabricated metals and paper industries did overall emissions 
decrease, and releases in the chemicals and primary metals industry actually increased. Moreover, reductions in releases in the fabricated metals industry were due to off-site transfers to recyclers, not source reduction, the preferred method under the program (Gamper-Rabindran 2006).

If 33/50's benefit to society came from incremental reduction in toxic releases, the primary benefit EPA offered participants was recognition - literally a certificate of appreciation mailed a few weeks after EPA received a company's letter of commitment. Companies could display their EPA certificates of appreciation in their headquarters' lobbies. EPA also included the names of participating companies in its annual Progress Update Reports and other publications. In the later years of the program, EPA decided to allow companies to submit "success stories” describing their environmental efforts, stories that EPA then disseminated. EPA also much later decided to cooperate with the publisher McGraw-Hill on a more selective awards program, called "Environmental Champions," based on corporate-level performance as measured in TRI reports. The 33/50 program was officially "enforcement neutral," which is to say that EPA did not offer any regulatory relief or enforcement discretion to participants. ${ }^{4}$

The simplicity of 33/50's joining requirements made it easy for businesses to participate in this club, but those simple requirements also made it more difficult for EPA to demonstrate the program's credibility. 33/50 failed to win the support of the national environmental community which had actively sought a stronger voluntary program that would have promoted reductions in the use - not just release - of toxic chemicals instead. Environmental groups were also concerned that companies could reduce releases in the

\footnotetext{
${ }^{4}$ Sam \& Innes' (2005) finding that participants were subject to less frequent inspections suggests that in practice 33/50 members may have reaped some decreased regulatory scrutiny.
} 
target chemicals by switching to other toxic chemicals or by making "paper reductions" based on different estimation techniques rather than based on real environmental gains. Rather than recognize companies simply for making a commitment, environmentalists urged that EPA require companies to submit additional documentation on their use reduction efforts before being recognized under this program. Although they were not opposed to the idea of a voluntary pollution prevention program, they wanted to see that the program could achieve genuine and well-documented environmental results. Overall, environmentalists have not been convinced that $33 / 50$ had a significant impact on the environment, tending to see it as basically a public relations ploy.

\section{National Environmental Performance Track}

Five years after 33/50 came to an end, EPA launched its National Environmental Performance Track program. Like 33/50, Performance Track seeks to induce individual facilities to make measurable environmental improvements by recognizing and encouraging facilities that commit to going above and beyond what they are required to do by law. The standards for entry and ongoing participation, however, are significantly higher than 33/50. To qualify for membership in Performance Track, a facility must have implemented a formal, independently assessed environmental management system, demonstrate a history of past environmental achievements, have a record of sustained compliance with environmental regulations, be committed to improving its environmental performance, and engage in community outreach activities.

To encourage facilities to join this club, EPA initially contacted participants in its other voluntary programs, including 33/50. Two hundred twenty-seven facilities joined 
during the initial application round in 2000. Since then, Performance Track staff members have focused recruitment efforts in three areas: facilities that meet the program's environmental management system requirement, facilities that meet the program's compliance requirement, and facilities that express interest in the program at conferences the agency attends or organizes. EPA staff have routinely contacted managers of the nearly 5,600 facilities that are certified to ISO 14001, since these facilities already meet Performance Track’s management system requirement. A much larger number, approximately 65,000 facilities, satisfy Performance Track’s compliance requirement by having a generally clean record in EPA's enforcement database: several years ago, EPA sent program information to some of those facilities as well.

Performance Track staff also regularly attend and speak at a variety of professional and industry conferences in an effort to promote the program.

Performance Track reviews applications for new members twice each year. Since 2000, membership in Performance Track has grown by about $12 \%$ annually. As of October, 2008, membership stands at 548 facilities. While members represent a wide range of economic activities, four major manufacturing sectors make up the substantial portion of the program's membership: chemical products, electronic and other electric equipment, pharmaceuticals and medical equipment, and transportation equipment. However, many non-manufacturing facilities participate along with even a large number of public sector facilities (EPA 2007a).

Performance Track facilities tend to be located in relatively densely populated communities, where poverty levels are relatively low and people are relatively highly 
educated (BAH 2005). ${ }^{5}$ Performance Track facilities are diverse in terms of size. In 2004, about $12 \%$ of facilities had fewer than 50 employees, and nearly $20 \%$ had fewer than 100 (EPA 2006a). The remaining 80\% were distributed about evenly among the following size categories: 10-499 (29\%); 500-1000 (24\%); over 1000 (27\%) (EPA 2006a).

Slightly less than half of all Performance Track facilities (47\%) hold environmental permits under the Clean Water, Clean Air, or Resource Conservation and Recovery Acts (BAH 2005). ${ }^{6}$ About 30\% have been designated large quantity hazardous waste generators under the Resources Conservation and Recovery Act (RCRA), 25\% have been designated major sources of air pollution, $9 \%$ are major sources of water pollution, and 7\% are Hazardous Waste Treatment, Storage and Disposal Facilities (BAH 2005). About half of all Performance Track plants hold no major environmental permits (BAH 2005).

Costs of participation are considerably higher for Performance Track than they were for the 33/50 program. In order to join Performance Track, a facility must complete a 22-page application that asks questions about its location, size, and business sector, environmental management system, and past environmental accomplishments. The facility must describe four areas in which it promises to make future environmental commitments over the coming three years. Applications must include three community references and must be signed by a senior officer in the applying organization. EPA

\footnotetext{
${ }^{5}$ Information about demographic characteristics of Performance Track plants is taken from BAH (2005), which includes data from Performance Track facility applications through Round 7 (February 2004).

${ }^{6}$ Information about environmental permitting is taken from BAH (2005), which includes data from Performance Track facility applications through Round 7 (February 2004).
} 
reviews each application and conducts its own screening to ensure each facility is in compliance with federal, state, and local regulations.

Once accepted into Performance Track, a facility’s membership is good for three years, at which point it must reapply. EPA's expectation is that members will make progress toward achieving their performance commitments and thus the program also requires that members complete an 12-page annual performance report (APR). The APR, which must also be signed by the senior manager responsible for the facility, requires facilities to "normalize” their current performance vis-à-vis a baseline level. EPA posts facility APRs on its website and facility managers are expected to make the report generally available to the public. EPA headquarters and regional staff visit about $10 \%$ of member facilities annually to confirm application information and assess progress toward facilities’ commitments.

EPA claims that Performance Track’s positive social impacts have been significant. During the period 2000-2006, members reduced water consumption by 3.7 billion gallons, energy use by 4.3 million MMBTU, and hazardous waste generated by 52,266 tons (EPA 2008a). They conserved some 16,809 acres of land (EPA 2008a).

The results of the program have not yet been extensively reviewed by outside researchers, and as was true for 33/50, the key question is whether the reductions made by Performance Track facilities would have otherwise occurred in the absence of the program. Presumably even facilities not in Performance Track have reasons to reduce their environmental impacts, especially in terms of their use of materials, energy, and water where improvements to environmental performance can also result in private cost savings. 
From EPA’s perspective, Performance Track offers three significant benefits to member facilities: (1) recognition, (2) networking opportunities, and (3) regulatory and administrative incentives. In the first benefits category, EPA offers several types of recognition. The agency lists members on its website, issues press releases announcing new members, and sends letters to relevant elected officials announcing a facility's acceptance to the program. EPA allows members to use the Performance Track logo at facility sites and in promotional materials. In addition, EPA has persuaded some social investment advisory firms to treat Performance Track membership as a factor in rating companies. Finally, the agency gives out several special awards only to Performance Track members (EPA 2006b).

The second benefits category includes a number of networking opportunities for Performance Track members. EPA occasionally invites member facilities to information sessions with senior EPA officials to discuss regulatory and administrative incentives. EPA organizes an annual members event, regional roundtables, and a mentoring program that matches current and potential Performance Track members to share information about the application process and improving environmental performance. In addition, members themselves have created a separate Performance Track Participants Association that works closely with EPA to support the program.

Finally, EPA works with state agencies to offer a variety of regulatory and administrative benefits to participating members. These include reducing some of the routine administrative costs of environmental regulation. For example, EPA has deemed Performance Track facilities to be a low priority for routine inspections. In addition, EPA gives at least two formal regulatory exemptions to Performance Track members 
(EPA 2004). First, members have to file reports less frequently under the Maximum Achievable Control Technology (MACT) hazardous air pollutant provisions of the Clean Air Act. Second, Performance Track facilities can accumulate hazardous wastes on-site for up to 180 days, and in some cases 270 days, without a RCRA permit (in comparison to the usual 90 days) (EPA 2004). In announcing these regulatory benefits, EPA estimated that overall facilities would stand to gain about $\$ 700,000$ over the next three years from reduced monitoring costs and increased flexibility, or on average about $\$ 1,350$ annually per facility (EPA 2004).

EPA has proposed offering additional modifications in regulatory requirements to Performance Track members. However, environmental advocacy organizations have sharply criticized such proposals, thus demonstrating the political climate within which government clubs operate. For example, in comments on EPA's 2005 proposal to expand Performance Track benefits, the Natural Resources Defense Council (NRDC) objected to incentives that would reduce monitoring, recordkeeping, and reporting for Performance Track members and would reduce EPA and state oversight (Walke 2005). The Environmental Integrity Project (EIP), a non-profit environmental organization, similarly called on EPA to step back from "ever more ambitious regulatory breaks" for Performance Track members (Ware 2006). Both NRDC and EIP raised concerns that Performance Track entry criteria fail to ensure that members demonstrate truly "superior" environmental performance that would warrant such benefits. In a letter to EPA Administrator Stephen Johnson, EIP and 30 other environmental organizations called on the agency to delay expanding Performance Track until it could "show that the program's 
[societal] benefits justify reducing oversight, relaxing legal requirements, or excusing violations of the law" (Schaeffer et al. 2006).

EPA disagrees with the environmentalists' criticisms, and it did issue a further exemption in 2006 that allows certain Performance Track plants to reduce the frequency with which they self-inspect their hazardous waste processing (EPA 2006d). However, even this form of regulatory relief is still markedly more modest than the regulatory benefits originally proposed by EPA when it created Performance Track.

In addition to criticisms from environmental groups, Performance Track has elicited broader concerns. It has received negative media coverage and criticisms from members of Congress (Coglianese \& Nash 2008). Even the agency's own Office of the Inspector General, an independent office charged with evaluating the agency’s programs, has voiced apprehensions similar to those of environmental groups. In a 2007 report, the Inspector General found that some members' environmental performance, in terms of regulatory compliance and releases of toxic chemicals, fell below the average performance for their sector. The Inspector General concluded that the participation of these underperforming facilities undermined the integrity of the program (EPA 2007b).

Although EPA’s Performance Track office has disputed the Inspector General’s criticisms (EPA 2007b), their very existence demonstrates a core vulnerability facing green clubs run by government. As government attempts to broaden the benefits offered to participants, it can expect pressure from both within and outside government to tighten the membership process to ensure participants are truly worthy of the benefits they receive. Given the political climate within which Performance Track and other government programs operate, it should come as little surprise that a program that offers 
more benefits than 33/50 should also have entry requirements more demanding than did $33 / 50$.

\section{Project XL}

EPA's design for Project XL was decidedly more ambitious than 33/50's and Performance Track’s. In the wake of a Republican sweep of Congressional elections in 1994, President Bill Clinton and Vice President Al Gore announced Project XL as part of an initiative to "to develop innovative alternatives to the current regulatory system" (Clinton \& Gore 1995). EPA intended Project XL to encourage "eXcellence and Leadership” in environmental management - hence the name XL. Viewed at the time as EPA’s flagship voluntary program, Project XL sought to promote superior environmental results by offering participants individualized regulatory exemptions. EPA committed to considering proposals to waive virtually any regulatory requirement if an applicant facility could demonstrate that doing so would enable the facility to achieve superior environmental performance through alternative technologies or processes. ${ }^{7}$

Both Project XL and Performance Track trace their ideological roots to a set of discussions convened by the Aspen Institute in the early 1990s about alternatives to existing environmental regulation. One recommended alternative was to recognize and

\footnotetext{
${ }^{7}$ Some scholars might well characterize Project XL as a negotiated agreement as opposed to a green club (Delmas \& Marcus 2004, Carraro and Lévêque 1999). Project XL did involve negotiations with individual facilities, but the program also bears an affinity with other EPA voluntary programs in that it sought to encourage individual facilities with records of strong regulatory compliance to cooperate with EPA, states, and environmental or community organizations and experiment with new ways to achieve superior environmental performance. We therefore follow Prakash and Potoski (2006, 63-65) in treating Project XL as an example of a green club.
} 
treat differently organizations if they meet high standards and pledge to attain "superior environmental performance” (Aspen Institute 1994, 4). While the Aspen Institute did not use the language of club theory, in essence it was proposing the establishment of a government club for environmental leaders for whom usual regulatory requirements would not apply. In addition to favorable publicity, government would provide participants “increased flexibility as to how the environmental goals are achieved” and waivers of some regulatory requirements (Aspen Institute 1994, 4).

In announcing Project XL, EPA stated its intention "to give regulated sources the flexibility to develop alternative regulatory strategies that will replace or modify specific regulatory requirements on the condition that they produce greater environmental benefits” (EPA 1995b). The agency established a detailed set of criteria for facilities seeking to qualify for benefits under Project XL. To be eligible, facilities were required to demonstrate superior environmental performance improvements, reduce paperwork and cost, involve outside constituencies, prevent pollution in multiple media, establish measurable objectives, and broadly disseminate information. Facilities seeking regulatory flexibility under Project XL would first submit a proposal to the federal Regulatory Reinvention Docket. A team of EPA headquarters, regional, and state agency staff members would review each proposal to determine if it merited further consideration. If so, the facility could then decide whether to adapt its proposal in response to EPA feedback - usually by providing substantial additional information. If the facility chose to develop its proposal further, EPA would then determine whether the revised proposal met the stated criteria for Project XL. If it cleared this hurdle, a proposal would come before the Associate Administrator for Reinvention, who would 
consult with other EPA personnel before deciding whether to advance the proposal. At this point, the agency and the proposing facility would start developing a "Final Project Agreement,” a negotiation that also included officials from the applicable state and local governments as well as representatives from interested environmental and community groups (EPA 1995b). If negotiations among these varied players yielded a consensus, EPA and the facility would draw up a contract describing the project in detail (Caballero 1998).

When Project XL was first announced, many agency officials anticipated attracting an extensive competition among project proposals. President Clinton even declared that EPA would complete 50 Project XL agreements within the first year. However, the agency received far fewer applications than expected. It was not until December, 2000, five years after the program launch, when EPA could announce that it reached its fiftieth Project XL agreement. Even two years later, when EPA announced that it would be permanently closing down Project XL, it had only completed a handful of additional agreements.

Project XL was open to any organization subject to EPA regulation. Early Project XL participants were mostly large businesses. The first members, announced by President Clinton in the fall of 1995, included facilities operated by 3M, Hadco, Intel, Lucent, and Merck, as well as by two public entities, the South Coast Air Quality Management District and the Minnesota Pollution Control Agency (Lund 2000). Over time, Project XL's membership shifted to include still larger numbers of public-sector organizations including cities, post offices, and sewer authorities. By October 2000, 
about half of all Project XL members were public facilities (Marcus et al. 2005). ${ }^{8}$ In Project XL's later years, businesses seem "to have shied away from becoming involved in XL” (Marcus et al. 2005, 300) due to the high costs and controversy surrounding the program.

Project XL was plagued with "process barriers" (Marcus et al. 2002). An EPA $(1998,41)$ review found that "[m]ost stakeholders commented the process was too long or much longer than they expected or felt was warranted.” Negotiation of final agreements often required thousands of hours of time over many months (Marcus et al. 2002). The average duration needed to complete final agreements was 26 months (Delmas \& Marcus 2004). EPA emphasized from the start the importance of obtaining support from community and environmental advocacy groups before it would approve an XL application, even though involvement of these groups proved cumbersome. In addition, after the applicant secured agreement from EPA, state regulators, community groups, and environmentalists, EPA then proceeded to develop a site-specific rulemaking to implement the regulatory waiver sought by the applicant, a rulemaking processed in Washington through the normal notice-and-comment procedures including publication in the Federal Register (Caballero 1998; Hirsch 1998).

According to an independent study of eleven of the earliest XL projects, the process of developing proposals and securing agreement imposed significant costs on businesses, averaging about $\$ 350,000$ per proposal and rising to more than $\$ 500,000$ in some cases (Blackman \& Mazurek 1999). The most costly parts of the process were interacting with EPA at both the regional and federal levels. Together, these interactions were responsible for half the costs to companies of advancing an XL proposal (Blackman

\footnotetext{
${ }^{8}$ For a list of Project XL agreements, see: http://www.epa.gov/ProjectXL/projects.htm
} 
\& Mazurek 1999). Costs to EPA were also substantial. Not counting the costs to EPA headquarters to run the program overall, EPA regional offices spent on average about $\$ 111,000$ to negotiate and approve each proposal, and in some cases costs reached about $\$ 200,000$ per proposal (Blackman \& Mazurek 1999). Costs were greatest for complex and innovative projects - "precisely the type of proposals that Project XL was designed to foster in order to improve the efficiency of the regulatory system” (Blackman \& Mazurek 1999, 1). Companies were discouraged by the high transaction costs of participation, time-consuming review process, and complex negotiations required with a seemingly vast array of interest groups (Davies \& Mazurek 1996).

In an effort to gauge the cumulative environmental benefits from Project XL, EPA has attempted to aggregate the environmental benefits listed in approved project proposals. Assuming these proposals accurately predicted actual environmental impacts, the cumulative benefits of 19 such projects over the period 1997-2001 included the elimination of as much as 28,319 tons of criteria pollutants, 2,467 tons of VOC emissions, and 467 tons of hazardous air pollutants, as well as the recycling of 20,540 tons of solid waste (EPA 2001). EPA also claimed that the program was also associated with a number of community benefits. Since people living near a Project XL facility were invited to participate in decision making about environmental management, they presumably enjoyed increased access to information about facility environmental impacts and operations (EPA 2001).

The benefits to the organizations that completed XL agreements with EPA varied. Of course, as the program's name implies, EPA gave recognition to participants for their “excellence and leadership,” something EPA has claimed was "very helpful in improving 
relations with regulatory agencies and communities and in meeting the expectations of environmentally conscious consumers and shareholders” (EPA 2001, 5). The waivers EPA promised Project XL participants were more substantial than the regulatory incentives provided through Performance Track. Intel's Project XL agreement, for example, allowed it to reduce the time to secure environmental permits for one of its semiconductor manufacturing facilities in Arizona. By eliminating the need for a permit every time the plant changed manufacturing processes to bring new products to market, the company was able to eliminate some 30 to 50 reviews annually (Lund 2000). Intel's cost savings were substantial, estimated to be upwards in the millions of dollars, because permit delays were a key concern for a firm producing products in the fast-paced computer technology marketplace (Lund 2000).

Despite the fact that Project XL involved only a modest number of participating facilities, it generated widespread controversy similar to that sparked by Performance Track and, to a lesser extent, the 33/50 program (Susskind \& Secunda 1998). For example, frequent complaints arose over the vague and contested nature of the Project's mission to achieve "superior environmental performance" (Marcus et al. 2002). Was "superior" to be understood relative to the level imposed by law on a facility or to its actual level of performance, which could already be cleaner than legally required? If a company were already performing better than standards allowed, did it need to go further beyond compliance to secure an XL agreement? Or was it sufficient to continue to achieve any level of performance better than the regulatory standards, even if worse than before the agreement? Businesses preferred the latter, while environmentalists the former. The agency frequently found itself in the middle. 
In addition, critics both inside and outside EPA charged that the program violated the law, since it was far from clear how EPA had the authority to waive statutory requirements. It became commonplace to quip, “If it isn’t illegal, it isn’t XL” (Caballero 1998). Many at EPA saw Project XL “as a threat” to the environmental regulatory system that they were charged with upholding (Susskind \& Secunda 1998, 96). Aware that even one major environmental problem arising from an XL Project had the potential to discredit EPA and all XL facilities, agency officials painstakingly scrutinized XL proposals. Environmental advocacy groups viewed Project XL with suspicion, with some apparently claiming that “XL” stood for “EXtra Leniency” (Steinzor 1998,125). Among other things, they feared that "business would subvert XL by offering EPA multimedia emissions trade-offs that could pose new and more serious hazards to workers and the environment” (Susskind \& Secunda 1998).

\section{Program Design and Participation}

Although 33/50, Performance Track, and Project XL were all examples of green clubs, they exhibited striking differences in their overall design. The requirements for entry into these program varied considerably, ranging in increasing stringency from a minimal letter of general commitment for 33/50, to completion of an extensive application and documentation of multiple beyond-compliance commitments for Performance Track, to an application process followed by an intensive multi-stakeholder negotiation followed by a site-specific rulemaking for Project XL. As the entry stringency increased across these three programs, participation levels declined, from over 1,300 in 33/50 to about 550 in Performance Track to about 50 in Project XL. 
What explains these varied levels of stringency? The insights of principal-agent theory should lead us to expect that the stringency of entry requirements for government clubs will be affected by the level of recognition and rewards to the participants of these programs. The standard principal-agent problem arises when individuals or organizations delegate authority to third parties (agents) to act on their behalf, since principals do not fully control their agents and agents' interests are not always fully aligned with those of their principals (Zeckhauser \& Pratt 1985). While government regulators certainly do not make participants in clubs their agents per se, they do give participating businesses something valuable, namely the regulators' imprimatur. And like agents more generally, the businesses that participate do not have interests fully aligned with the government's. A principal whose agent shirks (i.e., exploits his discretion to pursue his own interests rather than those of the principal) will harm the principal. Similarly, businesses that participate in a green club, and thereby receive government recognition if not even exemption from normal regulations, can harm the government agency if they later are found to have created serious environmental problems or have violated normal environmental regulations.

A regulatory agency assumes a risk to its own reputation, and more importantly a risk to its standing with its political overseers and the source of its budgetary appropriations, when it recognizes a facility or firm for some action of environmental leadership. As the agency gives businesses greater recognition and rewards, it also assumes a greater exposure to risk itself. We have seen that each of the three programs failed to receive enthusiastic support from environmental organizations. Significantly, environmentalist criticisms grew stronger as EPA gave, or proposed giving, members 
greater regulatory incentives. Since bureaucracies tend to be risk averse, we can expect they will be sensitive to criticisms that their programs are recognizing and rewarding the wrong companies or that their claims of environmental gains from the programs lack credibility. In addition, for any given business an agency recognizes or rewards, there is at least a small potential that the business will later create a significant environmental problem or have an accident or fatality on site. Any regulatory agency that creates a club for "leaders" inherently risks public and political embarrassment should such an incident occur - not to mention the resulting legislative hearings and the potential for legislative termination of voluntary programs, their appropriations, or other political repercussions.

The underlying general problem for principals in controlling their agents is an informational one. The principal usually does not know nearly as much as the agent does, nor can the principal fully know everything about the agent's actions. This informational asymmetry gives rise to various solutions that seek either to overcome this asymmetry or to help encourage the agent to see it in her interests to serve the principal's interests. These solutions include: (1) contracting, (2) monitoring, (3) power-sharing, and (4) reversibility (Coglianese \& Nicolaidis 2001). Through contracting, principals either create incentive structures that realign agents' incentives with the principals' interests, or that delineate the authority granted to the agent so that it is defined in a way that restricts departures from the principals' interests. Monitoring refers to reporting and other mechanisms designed to overcome the information asymmetry that afflicts principals. Under power-sharing arrangements, agents must get authorization from or otherwise involve their principals in final decisions. And reversibility mechanisms allow principals 
the opportunity to override agents’ decisions and even to terminate the agency relationship.

When government agencies recognize and reward industry, their underlying informational problem is the same as that of any principal. How does EPA know if a business it decides to recognize for reducing pollution will actually do what it commits to do? How will it know the business will not later turn out to be (or to create) an environmental disaster that embarrasses the agency and subjects it to accusations of having cozied up to industry? The solutions for the regulator's problem are similar to the kinds of contracting, monitoring, power-sharing, and reversibility used in addressing principal-agent problems more generally. The entry requirements government imposes on prospective club members and the overall terms and conditions for participation reflect these kinds of solutions. Under Performance Track, for example, EPA monitors facility environmental performance by requiring managers to complete a relatively lengthy application, by visiting the participating facility, and by reviewing annual progress reports. It also reserves the right to end the membership of any facility that does not live up to program requirements, and it has exercised this discretion on numerous occasions. Under Project XL, EPA added a power-sharing mechanism, not only requiring buy-in by community groups and environmentalists, but also retaining authority to reject the terms of a final project agreement.

For the same kinds of reasons that underlie principal-agent theory, then, we can expect that the greater the reward an agency gives to businesses who participate in government clubs, the greater will be the stringency of the club’s entry requirements. That appears to be exactly what we observe with 33/50, Performance Track, and Project 
XL. The stringency of the entry requirements into these three clubs corresponds to the level of reward and recognition each program provided to participants. Under the 33/50 program, EPA simply provided participants with a certificate of membership, and so entry requirements were minimal. Under Performance Track, EPA has offered participants higher profile recognition by listing on the agency’s website - as well as annual meetings with high-level EPA officials and modest exemptions on certain regulatory requirements. Performance Track’s entry requirements are correspondingly more stringent than 33/50's. Under Project XL, EPA promised participants a still more substantial benefit - namely, actual waivers from substantive environmental standards and its entry requirements were the most stringent and intensive of all. Furthermore, as we have seen, as entry stringency increased across each of these three clubs, business participation declined, notwithstanding the changes in the level of rewards.

\section{Design and Participation Across All EPA Partnership Programs}

Do the relationships between government rewards, entry stringency, and business participation generalize beyond the cases of 33/50, Performance Track, and Project XL? We believe they do. To assess the general validity of the conclusions drawn from these three cases, we collected and analyzed data on all similar EPA clubs that were in existence in 2004.

We began our study by identifying and reviewing all of the national voluntary programs currently administered by EPA. ${ }^{9}$ As one might imagine, what EPA designates

\footnotetext{
${ }^{9}$ We examined all the programs listed on EPA's website as voluntary programs: http://www.epa.gov/partners/. In addition, we reviewed those listed on internal documents we obtained from EPA staff. All the programs were national programs; we excluded exclusively
} 
as a "voluntary program” can mean several things. EPA appears to consider as a

voluntary program any agency effort that is designed to induce firms or facilities to

undertake "voluntary" action, that is, action that goes beyond current regulations or is not

even addressed by current regulations. This category includes educational programs, grants, competitive awards, product certifications, and partnership programs. Of the

several types of voluntary programs, we consider only partnership programs as

constituting government clubs. ${ }^{10}$

In a partnership program, EPA establishes criteria for designating some firms or facilities as “members.” Membership requires organizations to make some kind of commitment or other demonstration, and in return EPA offers members some benefit or package of benefits. ${ }^{11}$ Of all the EPA voluntary programs we examined, 29 could be classified as voluntary partnership programs - that is, clubs. A complete list of these clubs is provided in Table 8.1. Notwithstanding the actual names EPA has given these

regional voluntary programs. We did not include any past EPA programs, such as 33/50 or Project XL, that the agency no longer considered active. In total, we examined 62 programs. Data collection took place in October, 2005.

${ }^{10}$ Confusingly, EPA sometimes refers to all of its voluntary programs as "partnerships." We use the term partnership program in a more restricted sense, as a standardized program that enables an exchange between EPA and a regulated entity. EPA offers a package of benefits (usually recognition) in exchange for certain types of beyond-compliance activities on the part of the facility. To be clear, we distinguish partnership programs from the following four alternative types of voluntary programs. Educational programs offer educational resources to firms, local governments, non-governmental organizations, and citizens. Resources take the form of publications or websites that inform parties of environmentally benign ways of operating. The "It All Adds Up to Clean Air" program is an example. Grants provide financial support for projects that demonstrate beyond-compliance practices, and we considered technical assistance programs as a grant-in-kind to businesses. EPA's AgSTAR Program is an example. Competitive Awards recognize firms that distinguish themselves beyond their peers. These are competitive, one-time awards, not a sustained partnership. EPA's Clean Water Act Recognition Program is an example. Product Certifications seek to promote a market in "green" products by developing standards for the environmental characteristics of these products and a process for certifying that specific products meet these standards. The part of the EnergyStar program that establishes standards for energy-efficient appliances is an example.

${ }^{11}$ Unlike with product certification, in voluntary partnership programs the membership decision is made based on qualities of the organization, not the product. 
Table 8.1: National EPA Voluntary Partnership Programs (2004)

- Best Workplaces for Commuters

- Climate Leaders

- Coal Combustion Products Partnership

- Combined Heat and Power Partnership

- ENERGY STAR Business Improvement

- Green Power Partnership

- GreenScapes

- High Production Volume Challenge

- Indoor Air Quality Tools for Schools - Great Start Awards Program

- Indoor Air Quality Tools for Schools - Leadership Awards Program

- Labs 21

- Landfill Methane Outreach Program

- Methane to Markets Partnership

- Mobile Air Conditioning Climate Protection Partnership

- National Environmental Performance Track

- National Partnership for Environmental Priorities

- Natural Gas STAR Program

- Partnership for Safe Water

- Pesticide Environmental Stewardship Program

- PFC Emission Reduction Partnerships

- Plug-In to eCycling

- SF-6 Emission Reduction Partnership for Electric Power Systems

- SF-6 Emission Reduction Partnership for Magnesium Industry

- SmartWay Transport Partnership

- Sunwise School Program

- Sustainable Futures

- Voluntary Aluminium Industrial Partnership

- Voluntary Children's Chemical Evaluation Program

- WasteWise 
programs, each has an element of exchange or agreement between the applicant and the government. Even the two programs labeled as "awards" programs were in fact partnership programs in the sense we mean, since the awards are not limited or competitive but instead are available to any qualifying applicant. ${ }^{12}$

For each of the programs in Table 8.1, we reviewed official program material describing the application process and the qualifications for membership. Three researchers (the two authors and a graduate student) participated in coding the stringency of each program's entry requirements, with differences in coding reconciled through agreement and further investigation. In cases where there was uncertainty in the written materials, we contacted EPA staff responsible for administering the programs.

We coded programs on a three-point scale for their entry stringency. Programs rated at " 1 " (lowest stringency) only called for participants to send in a short note or complete a brief application making a commitment to undertaking a voluntary action much like 33/50. For example, to join the SunWise School Program, a school need only provide EPA with contact information, promise to increase awareness of the dangers of sun exposure by trying at least one of five suggested activities, and briefly describe how it intends to use information EPA provides about avoiding sun exposure.

Programs rated "2" required both commitment and action, such as a description of a project or other undertaking that demonstrates the participant's commitment. For

\footnotetext{
${ }^{12}$ Our list includes the nine programs Fiorino (2008) describes, with the exception of WaterSense which EPA began in 2006, after we collected our data. We include 20 additional programs that fit the definition of partnership programs we use. Through these programs, EPA designates some firms as "members" that are required to commit to specific practices which EPA rewards with defined benefits. While Fiorino (2008) includes the entire Energy Star program (which includes a product certification program), our analysis includes only the Energy Star Business Improvement program, a component of Energy Star for business operations.
} 
example, the Best Workplaces for Commuting program recognizes companies that encourage employees to get to work in ways other than by drive-alone commuting. It requires prospective members to complete a three-page checklist that provides information about the employer's actions to promote car-pooling and public transportation. Each year, an employer must complete an eight-page update form describing the benefits it has provided to commuters. To join SmartWay Transport Partners, another EPA partnership program rated a "2," businesses must complete a twopage application committing to use EPA's performance model to measure their vehicle fleets' environmental performance, set specific and measurable performance goals, develop action plans for implementing the goals, submit the goals and action plans to EPA, and report progress. Most programs were like these examples, in that they required both a commitment and some demonstration or declaration of action, however minor.

Programs rated “3” also require commitment and demonstration of action, but they also involved training or screening by EPA or a third party to verify the applicant meets the qualifications. The National Environmental Performance Track, described in the previous section, illustrates this highest level of stringency. Facilities wishing to join Performance Track must clear a compliance screening by the agency, meet eligibility requirements, commit to improve performance in four areas, and complete a 29-page application and an 11-page annual report. The Sustainable Futures program also imposes substantial procedural and substantive requirements on prospective participants. To be eligible for relief from certain Toxic Substances Control Act (TSCA) testing


day training program to learn about EPA's Pollution Prevention Framework. Facilities 
must then use EPA's framework to assess the risks associated with new chemicals they plan to develop and show they are using the framework in making product development decisions. They must submit to EPA between five and ten assessments that include their views about how well EPA's framework helped in comparing alternatives and selecting more benign chemicals.

In addition to entry stringency, we also coded programs based on the benefits they offered members. For most of the programs, the benefits were basically the same: public recognition (including listing on EPA's website); a plaque, logo, or certificate; a point of contact with EPA; and access to technical assistance or educational materials. Only one program offered less than these benefits, the SunWise program, which does not even list participating schools on EPA's website. We rated it a “1” for its level of benefits. A handful of programs offered benefits exceeding the basic package, in particular offering some form of regulatory relief; these programs we rated a "3" for level of benefits.

Finally, we collected data on the number of members of each partnership program. For most programs, members were listed on the EPA's website, so we used the number of members contained on those lists as of the end of October 2005 for our analysis. Where no lists were posted we contacted EPA to obtain current data. For those programs that distinguished members based on their sector or organization type, we aggregated members from across all categories and used the total membership numbers.

The basic contours of our data are consistent with the theoretical expectations growing out of our examination of 33/50, Performance Track, and Project XL. Programs with low entry stringency do not offer high benefits, and programs with high entry stringency tend to have high benefits. Of course, as Figure 8.1 shows, the variation 
between entry stringency and program benefits is not significant because more than half of the programs provide the "standard" package of program benefits and also provide a typical level of entry stringency requiring both a commitment and some action on the part of members. A few programs with low entry stringency offer medium benefits, but none offers a high level of benefits. Similarly, most of programs with high stringency also provide high levels of benefits.

\section{Figure 8.1 \\ Matching Entry Stringency to Benefits}

\begin{tabular}{lc|c|c|c|} 
& & \multicolumn{3}{c}{ Benefits } \\
\cline { 3 - 5 } & & Low & Med & High \\
\cline { 3 - 5 } Entry Stringency & 1 & 5 & 0 \\
\cline { 3 - 5 } & Med & 0 & 18 & 1 \\
\cline { 3 - 5 } & High & 0 & 0 & 3 \\
\cline { 2 - 5 } & & &
\end{tabular}

As expected, the degree of entry stringency is inversely related to the number of members (Figure 8.2). That is, the average membership in programs with low stringency is higher than the average membership in those with high stringency. Even taking into account the fact that some programs are older than others, the average number of members per year is higher for those programs with lower entry stringency.

Admittedly, even though we have examined all of EPA’s existing voluntary partnership programs, the overall numbers in this sample are low. The average membership level for programs with low stringency is no doubt dramatically affected by a single program - SunWise - which boasts about 13,000 members. That program, 
Figure 8.2

Average Membership by Membership Entry Stringency

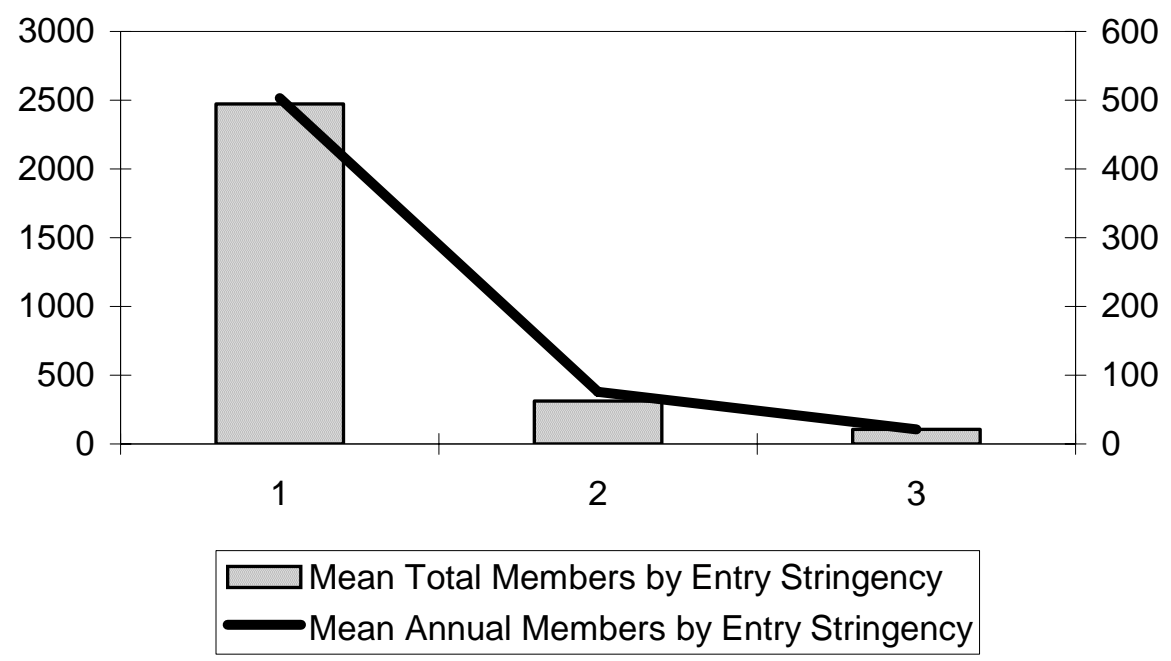

though, seems instructive: it offers no benefits to members beyond some educational materials, and despite a stipulation requiring members to participate in a student and teacher evaluation, it really demands nothing other than completing an on-line form with contact information. $^{13}$

At the other extreme from SunWise lies the Sustainable Futures program. As noted, Sustainable Futures requires that prospective members send representatives to a multi-day training course, conduct extensive risks assessments, and go through EPA screening, but in exchange it offers expedited regulatory relief from TSCA testing

\footnotetext{
${ }^{13}$ Were it not for the fact that EPA clearly treats this as a partnership program, replete with membership requirements that make the program a club, we probably would have characterized SunWise as an educational program.
} 
protocols. Although nearly three years old at the time of our data collection, the program had attracted only three businesses that have qualified for regulatory relief.

In between these extremes, the bulk of the programs appear to be "middle of the road" - both in terms of entry stringency and benefits. The membership levels appear quite modest. The average number of members per year for all these programs is 157 , with a standard deviation of 495 . Dropping the programs with the highest and lowest number of members, the average number of members per year is 72 , with a standard deviation of 96.

Given the sample size, we do not control for other factors that would seem likely to affect variation in membership levels across partnership programs, including: the number of firms or facilities that could be potential members; the underlying costs and benefits of the kind of environmental controls encouraged by the program; the existence of regulatory or other liability pressures that might additionally encourage businesses to undertake the actions called for by members; the degree of aggressiveness with which EPA promotes the program; and the probability of EPA taking regulatory action on issues related to the program and the costliness that any likely regulatory action would have for affected entities. We certainly do not pretend to have developed a full model explaining variation in membership levels across businesses, nor can we say how much of this variation can be explained by entry stringency.

However, there is one interesting comparison among EPA's programs that appears to be a natural experiment. The EPA’s Indoor Air Quality Tools for Schools program has two membership levels: the Great Start Awards (low stringency, moderate benefits) and the Leadership Awards (moderate stringency, moderate benefits). Neither 
program has attracted many members, but they do target the same kinds of organizations (school districts), address the same set of environmental issues, and operate within the same regulatory climate. Consistent with expectations, the lower stringency Great Start Awards level has attracted about 25\% more members than has the Leadership Awards level (54 versus 44, respectively).

\section{Conclusion}

Potoski and Prakash (2008) have explained that effective clubs develop strategies to attract new members and ensure that they meet club standards. If industry and nongovernmental organizations are able to create clubs that meet these two challenges, then government should presumably be able to do so as well. In practice, however, government faces potentially distinctive constraints that make it difficult, if not impossible, to use green clubs to induce both high levels participation and high levels of environmental improvement. EPA has tended to design its programs so that entry stringency increases with reward. As a result, the addition of rewards corresponds with a reduction in participation.

This counterintuitive result appears to be a function of how government tries to manage the risks of publicly recognizing and rewarding businesses that it is otherwise charged with regulating. Moreover, it appears that EPA and business managers place different value on the rewards and information demands associated with participation in government clubs. The regulatory incentives EPA has worked to provide as part of Performance Track, for example, have been significant enough to generate criticism 
of EPA by environmentalists, members of Congress, and EPA's own Inspector General. Yet for many businesses, the program's regulatory relief is trivial, if not entirely inconsequential. Some environmental managers have even told us that having hazardous waste stored on-site longer, as Performance Track allows, is actually a way to increase their risks of a spill or accident - as well as their concomitant risks of some future tort liability associated with that waste.

Although much work remains to explain the variation in participation across different green clubs run by government, the case studies and data we present in this paper show that fewer firms will assume the increased costs associated with gaining entry to clubs with higher stringency, even when these clubs promise greater rewards. Even if the transaction costs associated with joining a program like Performance Track seem modest and reasonable to an outside observer, many of those in business find completing the EPA's 22-page application and 12-page annual progress report to be a significant enough burden to lead them to pass on applying to Performance Track. In principle, government agencies like EPA could presumably increase their rewards so dramatically that businesses would flock to join, even if the entry requirements were as stringent as those with Performance Track, Project XL, or Sustainable Futures. But the present political and legal reality is such that either government cannot offer rewards that substantial or, if it did, it would need to increase entry stringency still further.

Our analysis leads to the prediction that the level of participation in green clubs run by government will remain quite modest. If government moves to increase rewards, it will also be compelled to increase entry stringency. The net result will be to decrease 
or at least constrain program membership. While in theory government has substantial rewards to offer businesses that participate in its green clubs, in practice it only offers strong rewards to those willing to submit to exceedingly strong swords. Few businesses are eager to accept that bargain. 


\section{References}

Arora, Seema and Timothy N. Cason. 1995. “An Experiment in Voluntary Environmental Regulation: Participation in EPA's 33/50 Program,” Journal of Environmental Economics and Management 28(3): 271-86.

Arora, Seema and Timothy N. Cason. 1996. "Why Do Firms Volunteer to Exceed Environmental Regulations? Understanding Participation in EPA’s 33/50 Program,” Land Economics 72(4): 413-32.

Aspen Institute. 1994. The Alternative Path: A Cleaner, Cheaper Way to Protect and Enhance the Environment. Washington, DC: The Aspen Institute.

Bennear, Lori S. 2008. "What Do We Really Know? The Effect of Reporting Thresholds on Inferences Using Environmental Right-to-Know Data,” Regulation and Governance 2(3): 293-315.

Blackman, Allen and Janice Mazurek. 1999. The Cost of Developing Site-Specific Environmental Regulations: Evidence from EPA's Project XL, Resources for the Future Discussion Paper, 99-35-REV. Washington, D.C.: Resources for the Future.

Booz Allen Hamilton (BAH). 2005. Performance Track Database Report. A Joint Project of Booz Allen Hamilton and the Center for Business and Government, John F. Kennedy School of Government, Harvard University. On file with the authors.

Caballero, Thomas. 1998. “Project XL: Making it Legal, Making it Work,” Stanford Environmental Law Journal 17: 399-471.

Carraro, Carlo, and François Lévêque. 1999. "Introduction: The Rationale and Potential of Voluntary Approaches.” In Voluntary Approaches in Environmental Policy, Carlo Carraro and François Lévêque, eds. Boston: Kluwer Academic Publishers.

Clinton, William and Albert Gore. 1995. Reinventing Environmental Regulation. Washington, D.C.: U.S. Environmental Protection Agency’s Office of Policy Analysis and Review.

Coglianese, Cary and Jennifer Nash. 2008. “EPA’s National Environmental Performance Track: What is it Tracking? What is it Performing?” unpublished manuscript.

Coglianese, Cary and Kalypso Nicolaidis. 2001. "Securing Subsidiarity: The Institutional Design of Federalism in the United States and Europe.” In The Federal Vision: Legitimacy and Levels of Governance in the United States and the European Union, Kalypso Nicolaidis and Robert Howse, eds. New York: Oxford University Press. 
Davies, Terry and Jan Mazurek. 1996. “Industry Incentives for Environmental Improvement: Evaluation of U.S. Federal Initiatives,” Global Environmental Management Initiative, September 1996.

Delmas, Magali, and Arturo Keller. 2005. "Free Riding in Voluntary Programs: The Case of the U.S. EPA WasteWise Program,” Policy Sciences 38(2): 91-106.

Delmas, Magali A. and Alfred Marcus. 2004. “Firms’ Choice of Regulatory Instruments to Reduce Pollution: A Transaction Cost Approach,” Working Paper Donald Bren School of Environmental Science and Management. Santa Barbara: University of California at Santa Barbara.

Delmas, Magali and Ann Terlaak. 2001. “A Framework for Analyzing Environmental Voluntary Agreements,” California Management Review 43(3): 44-63.

Fiorino, Daniel. 2008. “Green Clubs and Environmental Performance: A New Tool for Government.” In Matthew Potoski and Aseem Prakash, eds., Voluntary Programs: A Club Theory Approach. Cambridge: MIT Press.

Gamper-Rabindran, Shanti. 2006. Did the EPA's Voluntary Industrial Toxics Program Reduce Emissions? A GIS Analysis of Distributional Impacts and By-Media Analysis of Substitution. Journal of Environmental Economics and Management 52(1): 391-410.

Hirsch, Dennis D. 1998. “Bill \& Al’s XL-ent Adventure: An Analysis of the EPA's Legal Authority to Implement the Clinton Administration's Project XL," University of Illinois Law Review 1998(1): 129-172.

Khanna, Madhu. 2001. "Non-Mandatory Approaches to Environmental Protection,” Journal of Economic Surveys 15(3): 291-324.

Khanna, Madhu. 2006. “The U.S. 33/50 Voluntary Program: Its Design and Effectiveness.” In Reality Check: The Nature and Performance of Voluntary Environmental Programs in the United States, Europe, and Japan, Richard D. Morgenstern and William A. Pizer, eds. Washington, D.C.: Resources for the Future Press.

Khanna, Madhu and Lisa A. Damon. 1999. “EPA's Voluntary 33/50 Program: Impact on Toxic Releases and Economic Performance of Firms,” Journal of Economics and Management 37(1): 1-25.

Lund, Lisa C. 2000. "Project XL: Good for the Environment, Good for Business, Good for Communities,” ELR News \& Analysis 2-2000: 10140-10152. 
Lyon, Thomas P. and John W. Maxwell. 2002. "Voluntary Approaches to Environmental Regulation.” In Economic Institutions and Environmental Policy, Maurizio Franzini and Antonio Nicita, eds. Chippenham, UK: Ashgate Studies in Environmental Policy and Practice.

Lyon, Thomas P. and John W. Maxwell. 2004. Corporate Environmentalism and Public Policy. Cambridge: Cambridge University Press.

Marcus, Alfred, David Geffen, and Ken Sexton. 2002. Reinventing Environmental Regulation: Lessons from Project XL. Washington, D.C.: Resources for the Future/Johns Hopkins University Press.

Marcus, Alfred, David Geffen, and Ken Sexton. 2005. "Cooperative Environmental Regulation: Examining Project XL.” In Industrial Transformation:

Environmental Policy Innovation in the United States and Europe, Theo de Bruijn and Vicki Norberg-Bohm, eds. Cambridge, MA: MIT Press.

Morgenstern, Richard D. and William A. Pizer, eds. 2006. Reality Check: The Nature and Performance of Voluntary Environmental Programs in the United States, Europe, and Japan. Washington, D.C.: Resources for the Future Press.

Potoski, Matthew and Aseem Prakash. 2008. "Voluntary Clubs: An Introduction.” In Voluntary Programs: A Club Framework, Matthew Potoski and Aseem Prakash, eds. Cambridge, MA: MIT Press.

Prakash, Aseem, and Matthew Potoski. 2006. The Voluntary Environmentalists: Green Clubs, ISO 14001, and Voluntary Environmental Regulations. Cambridge, UK: Cambridge University Press.

Sam, Abdoul G., and Robert Innes. 2005. Voluntary Pollution Reductions and the Enforcement of Environmental Law: An Empirical Study of the 33/50 Program. Manuscript. Tucson: Department of Agricultural and Resource Economics, University of Arizona.

Schaeffer, Eric et al. 2006. Letter to the Honorable Stephen Johnson, Administrator, U.S. Environmental Protection Agency, January 25, 2006.

Segerson, Kathleen and Na Li. 1999. "Voluntary Approaches to Environmental Protection," in International Yearbook of Environmental and Resource Economics 1999/2000, H. Folmer and T. Tietenberg, eds. Cheltenham, UK: Edward Elgar.

Steinzor, Rena. 1998. "Reinventing Environmental Regulation: The Dangerous Journey from Command to Self-Control," Harvard Environmental Law Review 22(1): 103-202. 
Susskind, Lawrence E. and Joshua Secunda. 1998. "The Risks and the Advantages of Agency Discretion: Evidence From EPA's Project XL,” UCLA Journal of Environmental Law and Policy 17(1): 67-116.

U.S. Congress, Office of Technology Assessment. 1986. Serious Reduction of Hazardous Waste: For Pollution Prevention and Industrial Efficiency. OTA-ITE-317. Washington, D.C.: U.S. Government Printing Office.

U.S. Environmental Protection Agency (EPA). 1995a. 33/50 Program Progress Update: TRI Reporting Profiles for 33/50 Program Chemicals. Washington, D.C.: U.S. Environmental Protection Agency.

U.S. Environmental Protection Agency (EPA). 1995b. "Regulatory Reinvention (XL) Pilot Projects,” Federal Register 60: 27,282-90.

U.S. Environmental Protection Agency (EPA). 1998. Evaluation of Project XL Stakeholder Processes: Final Report. Washington, D.C.: U.S. Environmental Protection Agency.

U.S. Environmental Protection Agency (EPA). 1999. 33/50 Program: The Final Record. EPA-745-R-99-004. Washington, DC: U.S. Environmental Protection Agency.

U.S. Environmental Protection Agency (EPA). 2001. Project XL: Directory of Project Experiments and Results. EPA 100-R-01-003. Washington, DC: U.S. Environmental Protection Agency.

U.S. Environmental Protection Agency (EPA). 2004. "National Environmental Performance Track Program,” Federal Register 69: 21737-54.

U.S. Environmental Protection Agency (EPA). 2006a. Leading Change: Performance Track Fourth Annual Progress Report. Office of Policy, Economics, and Innovation (MC 1808T), EPA-100-R-06-001. Washington, D.C.: U.S. Environmental Protection Agency.

U.S. Environmental Protection Agency (EPA). 2006b. Performance Track Hall of Fame. Washington, D.C.: U.S. Environmental Protection Agency, available at http://www.epa.gov/performancetrack/benefits/halloffame.htm\#out (accessed September 22, 2006).

U.S. Environmental Protection Agency (EPA). 2006c. Performance Track/Office of Enforcement and Compliance Assurance Memo - October 29, 2003. Washington, D.C.: U.S. Environmental Protection Agency, available at http://www.epa.gov/performancetrack/benefits/oeca.pdf (accessed September 22, 2006). 
U.S. Environmental Protection Agency (EPA). 2006d. "Resource Conservation and Recovery Act Burden Reduction Initiative,” Federal Register 71: 16,862-915.

U.S. Environmental Protection Agency (EPA). 2007a. Today's Commitments. Tomorrow's World. Five Years of Environmental Leadership. EPA 100-R-07004. Washington, DC: EPA, available at http://www.epa.gov/performancetrack/downloads/PTPRreport_05final.pdf

U.S. Environmental Protection Agency, Office of the Inspector General (EPA). 2007b. Performance Track Could Improve Program Design and Management to Ensure Value. Report No. 2007-P-00013. Washington, D.C.: U.S. Environmental Protection Agency, available at http://www.epa.gov/oig/reports/2007/200703292007-P-00013.pdf.

U.S. Environmental Protection Agency (EPA). 2008a. Performance Track Sixth Annual Progress Report. Washington, DC: U.S. Environmental Protection Agency, available at http://www.epa.gov/performancetrack/downloads/PT_ProgRprt_2008.pdf

U.S. Environmental Protection Agency (EPA). 2008b. Performance Track Online Administrative Site (Password protected website for Performance Track members and agencies).

U.S. General Accounting Office (GAO). 1994. Toxic Substances: Status of EPA's Efforts to Reduce Toxic Releases. GAO/RCED-94-207. Washington, D.C.: U.S. General Accounting Office.

Walke, John. 2005. Letter to Administrator Johnson on Behalf of the Natural Resources Defense Council. Docket ID OA-2005-0003, November 3, 2005.

Ware, Patricia. 2006. “Benefits of 'Performance Track' Program in Question, Environmental Groups Says,” Environment Reporter 37(6): February 10, 2006.

Zeckhauser, Richard J. and John W. Pratt. 1985. "Principals and Agents: An Overview.” In Principals and Agents: The Structure of Business, John W. Pratt and Richard J. Zeckhauser, eds. Boston: Harvard Business School Press. 